\title{
Hydraulic characteristic of selected installation valves installed on various pipes materials
}

\author{
Krystyna Poręba ${ }^{1}$,Weronika Kowalczyk ${ }^{1}$, Marcin K. Widomski ${ }^{2,}$, and Anna Musz-Pomorska ${ }^{2}$ \\ ${ }^{1}$ Graduate of Lublin University of Technology \\ ${ }^{2}$ Faculty of Environmental Engineering, Lublin University of Technology, Lublin
}

\begin{abstract}
Presented studies covered determination of minor pressure losses and values of minor loss coefficients for two selected installation valves: water control globe valve and angle valve, both DN 15 . The tested valves were installed on three pipes, including PP 20x3.4 mm, PEX-Al-PEX 16x2.0 mm and Cu $15 \times 1.0 \mathrm{~mm}$. In order to reflect the real operating conditions of the angle valve, the elastic PVC pipe was used. Our researches were performed on the laboratory installation, for the variable flow rate. The obtained results of laboratory studies showed the clear dependence between minor pressure loss and minor loss coefficients of studied valves, and water flow rate (Reynolds number), degree of valves' closure and, in some cases, manner of valves installation and material of pipes. The greatest values of minor pressure loss coefficients, of mean values relevantly statistically grater, were determined for the tested valves installed on the PEX-Al-PEX pipeline.
\end{abstract}

\section{Introduction}

Pressure losses in local resistances in complex domestic installations like hot and cold water supply or heating, may cause a significant portion of the total losses (even 40-60\%) [1-4]. Therefore, their exact determination is essential to design the aforementioned installations properly. Nowadays, calculation of minor pressure losses based on the withdrawn Polish Standard PN-M34034:1976 [5], is additionally complicated by considerable amount of available materials and possible ways of connecting them, as well as diversity of fittings and very close location of the adjacent resistances. For the above reasons, values of minor pressure losses calculated basing on the minor loss coefficients contained in the withdrawn PN-M-34034:1976 [5], are not equal to the real values, reported in technical and scientific publications [3,6-14].

Water control globe valve and angle valve belong to the popular representatives of shutoff fitting widely assembled on domestic installations made of various materials. Values of minor loss coefficient suggested by fittings manufactures and literature reports (including researches) for control globe valve are within the range of $6.8-10[5,15-17]$ while scientific reports showed values up to $12-20$ [18].

Analogically, values of minor loss coefficient for angle valve, suggested by literature, are in the range of 2 - $7[5,15,16,19]$. Additionally, in calculation of minor pressure losses on those two tested valves, keeping in mind the considering resistances generated by couplings used in valve's assembly on a various pipe's materials is needed. Exemplary values of minor loss coefficients for straight pipe connections for various materials vary in range 0.25-1.8 [20-23]. Information about the method of taking into account the influence of the distance between neighboring local resistances on pressure losses are practically inaccessible for designers.

This work contains the results of studies of minor pressure losses and minor loss coefficients for variable degrees of valve closure and different values of flow rate. Researches were made for two shutoff valves, both DN 15, with different construction (globe valve and angle valve), installed on pipes made of three materials: PP, PEX-Al-PEX and $\mathrm{Cu}$.

\section{Materials and methods}

Water flow resistance's researches presented in this work were performed for two selected installation valves: water control globe valve and washing machine shutoff angle valve, both DN 15 . The tested valves, using separable threaded coupler, were installed on three different pipe's materials typically used in domestic installations like hot and cold water supply or heating. The following pipes were used in our researches:

Polypropylene pipe PP-R, 20x3.4 mm, internal diameter $13.2 \mathrm{~mm}, \mathrm{k}=0.007 \mathrm{~mm}, \mathrm{PN} 20,1 / 10$ bar, according to PN-EN ISO 15874-2:2005.

Multilayer, cross-linked polyethylene pipe PEX-AlPEX with aluminum insert $16 \times 2 \mathrm{~mm}$, internal diameter $12 \mathrm{~mm}, \mathrm{k}=0.007 \mathrm{~mm}$, maximal operational pressure $60^{\circ} \mathrm{C} / 10$ bar and $95^{\circ} \mathrm{C} / 6$ bar, according to DIN 4726 .

Copper pipe $\mathrm{Cu}$, temper condition $\mathrm{R} 220,15 \times 1 \mathrm{~mm}$, internal diameter $13 \mathrm{~mm}, \mathrm{k}=0.0015 \mathrm{~mm}$, according to EN 1057.

* Corresponding author: M.Widomski@pollub.pl 

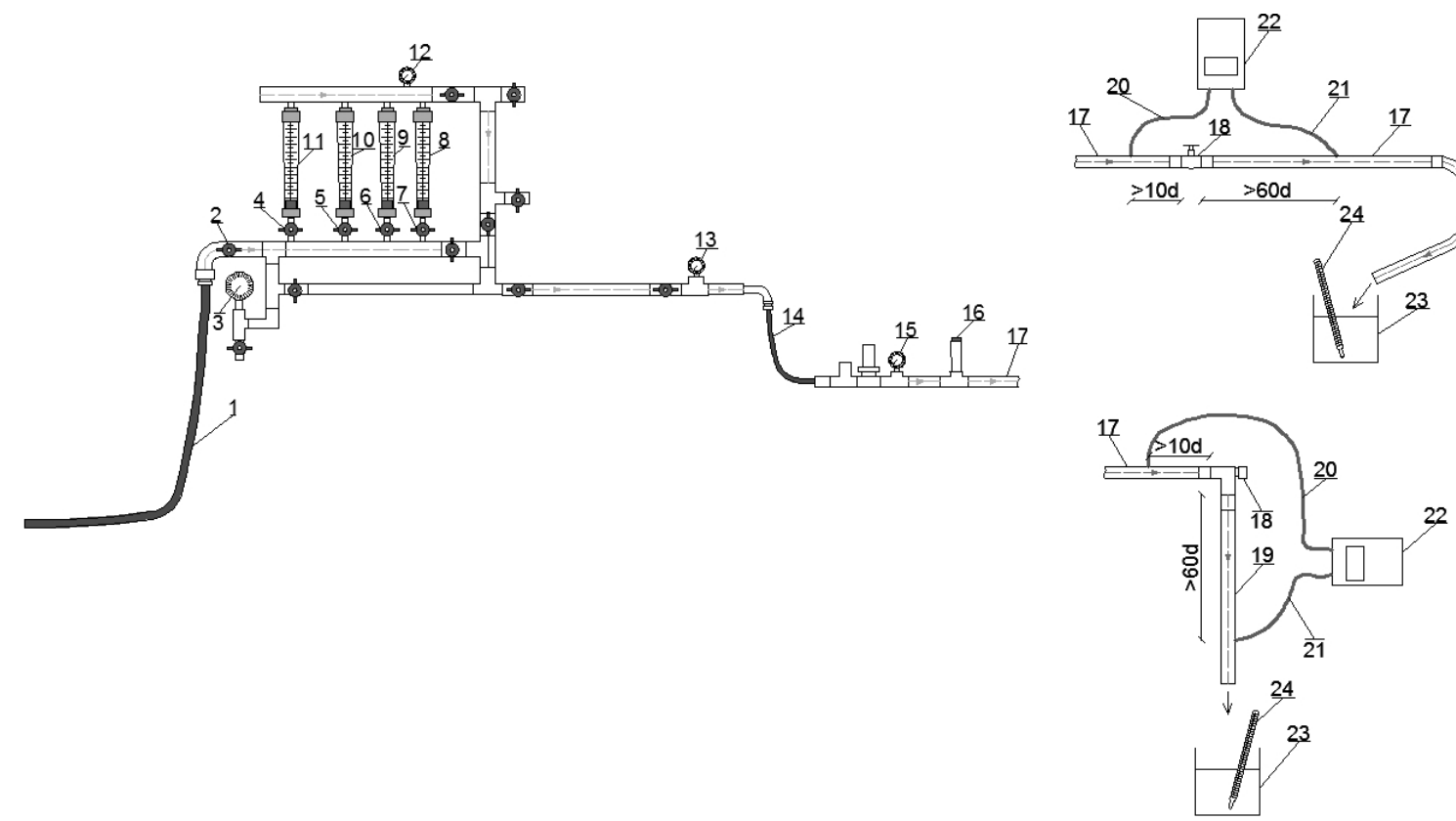

Fig. 1. Scheme of laboratory installation: 1 - elastic inflow pipe, 2 - valve, 3, 12, 13, 15 - manometers, 4, 5, 6 7 - valves, 8, 9, 10, 11 - rotameter, 14 - elastic pipe, 16 - air removal valve, 17 - PP, PEX-Al-PEX, Cu pipe, 18 - studied valve, 19 - PVC pipe, 20,21 impulse pipe, 22 - electronic differential manometer, 23 - glass, 24 - thermometer, 25 - elastic outflow pipe.

Additionally, in order to provide angle valve's real working conditions, elastic polyvinyl chloride pipe PVC for cold water $25^{\circ} \mathrm{C}$ with polymer threaded fittings, internal diameter $10 \mathrm{~mm}, \mathrm{k}=0.025 \mathrm{~mm}$ was used.

These researches were performed on the laboratory modular installation presented in Fig. 1. Installation consisted of measuring part involving set of interconnected rotameters and interchangeable research part made up of tested valves and the previously described pipes.

Tap water with monitored temperature to feed installation was uptaken from the internal water supply of the building through the reservoir. Set of rotameters used for flow rate measurement was consisted of four rotameters, class 4 , measuring range $20-200 \mathrm{dm}^{3} \cdot \mathrm{h}^{-1}$, $60-600 \mathrm{dm}^{3} \cdot \mathrm{h}^{-1}, 100-1000 \mathrm{dm}^{3} \cdot \mathrm{h}^{-1}$ and $60-600 \mathrm{dm}^{3}$. $\mathrm{h}^{-1}$. The rotameters used in the researches were tested by volumetric tank method.

Differences in pressure for selected sections in front and behind the tested valves were measured using the Lutron Electronic electronic differential pressure gauge (range: $0-20 \mathrm{mH}_{2} \mathrm{O}$, accuracy: $2 \%$ ) at distances of $10 \mathrm{~d}$ and $60 \mathrm{~d}[10,12]$ respectively, according to PN-EN 1267:2012 [24]. Measurement of flow resistances through the tested valves were performed for variable degrees of valve opening in the flow rate range of $100-$ $1560 \mathrm{dm}^{3} \cdot \mathrm{h}^{-1}$ corresponding to Reynolds number in the range of $2294-37202$ for globe valve and $100-1000$ $\mathrm{dm}^{3} \cdot \mathrm{h}^{-1}, \mathrm{Re}=2447-6151$ for angle valve. The following degrees of tested valve opening were used: $100 \%, 75 \%$, $50 \%$ and $25 \%$. Application of varying flow rates for both tested representatives of shutoff fitting was due to the difference in the observed minor pressure losses for both cases and the measuring range of the differential pressure gauges. All measuring series, for each flow rate, were performed in at least two repetitions. Determination of minor loss coefficients for tested valves was based on the Bernoulli equation transformation, respectively for each of the calculation schemes. For globe valve:

$$
\zeta=\frac{2 g \cdot \Delta h}{v^{2}}-\lambda \frac{\left(l_{1}+l_{2}\right)}{d}
$$

For angle valve:

$$
\zeta=\frac{2 g}{v_{2}^{2}}\left[\Lambda h-\frac{v_{2}^{2}-v_{1}^{2}}{2 g}-\left(\lambda_{1} \frac{l_{1}}{d_{1}} \cdot \frac{v_{1}^{2}}{2 g}+\lambda_{2} \frac{l_{2}}{d_{2}} \cdot \frac{v_{2}^{2}}{2 g}\right)\right]
$$

where:

$\varsigma$ - pressure loss coefficient [-];

$\Delta h$ - pressure losses read from the differential pressure gauge $\left[\mathrm{mH}_{2} \mathrm{O}\right]$;

$g$ - gravitational acceleration $\left[\mathrm{m} \cdot \mathrm{s}^{-2}\right]$, assumed to be $g=9.81\left[\mathrm{~m}^{\cdot} \mathrm{s}^{-2}\right]$

$v_{1}, v_{2}-$ mean velocity of the fluid flowing in the pipe in front and behind valve, for globe valve $v=v_{1}=v_{2}\left[\mathrm{~m} \cdot \mathrm{s}^{-1}\right]$;

$\lambda_{1}, \lambda_{2}-$ Darcy-Weisbach friction coefficient, for globe valve $\lambda=\lambda_{1}=\lambda_{2}[-]$;

$l_{1}, l_{2}$ - pipes lengths in front and behind valve (from the valve to the connection point of the differential pressure gauge) $[\mathrm{m}]$;

$d_{1}, d_{2}$ - pipe diameters in front and behind valve, for globe valve $d=d_{l}=d_{2}[\mathrm{~m}]$.

Darcy-Weisbach friction coefficients for each measurement were determined based on the ColebrookWhite equation, based on the Reynolds number (Re), the absolute pipe roughness $(\mathrm{k})$ and the internal diameter of the pipe.

Statistical analysis to assess significance of the observed differences between the average values of minor loss coefficients for the same degrees of opening 
of valves installed on various pipes materials, were based on standard statistical procedures: checking the normal distribution using the Shapiro-Wilk test, then assessing significance of the differences with Fisher ANOVA supplemented by Tukey post-hoc tests and non-parametric Kruskal-Wallis test with multiple comparisons.

\section{Results and discussion}

Results of presented researches covered determination of minor pressure losses and values of minor loss coefficients in relation to Reynolds number, for tested valves.

Fig. 2 and Fig. 3 present results of minor pressure losses measurement in relation to Reynolds number for two tested valves installed on each of the three used pipe materials. In both cases, there was a clear correlation observed between the value of minor pressure losses for the tested local resistances and change flow geometry caused by closure of the valves. In all tested cases, a significant increase in minor pressure losses for a given Reynolds number was observed with an increase in the degree of valve closure. For fully open globe valve, the pressure losses were in the range of $0.03-8 \mathrm{mH}_{2} \mathrm{O}$ for Reynolds number in the range, approx. $2400-39000$. Closing the valve to $25 \%$ of opening resulted in an increase in pressure losses to the range of $0.3-17$ $\mathrm{mH}_{2} \mathrm{O}$, for $\mathrm{Re}=2400-38000$. Similarly, for the angle valve, pressure losses increased from the range of $0.1-$ $8.9 \mathrm{mH}_{2} \mathrm{O}$ for full valve opening and $\mathrm{Re}=2500-29000$ to the range of $2.0-19.5 \mathrm{mH}_{2} \mathrm{O}$ for $25 \%$ of valve opening, $\mathrm{Re}=10000$. Additionally, it can be observed at graphs $\Delta h_{m}=\mathrm{f}(\mathrm{Re})$ presented in Fig. 2 and Fig. 3, that the highest values of resistances, for each of the degrees of tested valves opening, occurred in case of installing them on multilayer pipes PEX-Al-PEX.
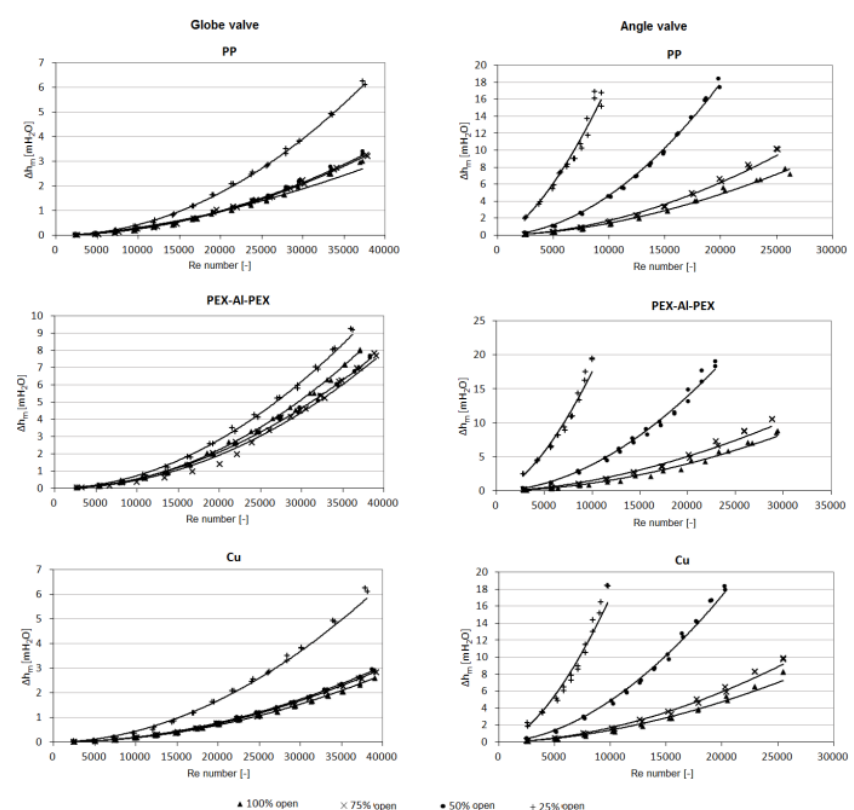

Fig. 2. Scheme of laboratory Minor pressure loss in relation to Reynolds number and degree of valve opening.
Results of calculations of values of minor loss coefficients $\varsigma$ for tested valves together with fittings are presented in Fig. 3. The characteristic values for the individual measurement series are summarized in Tab. 1.
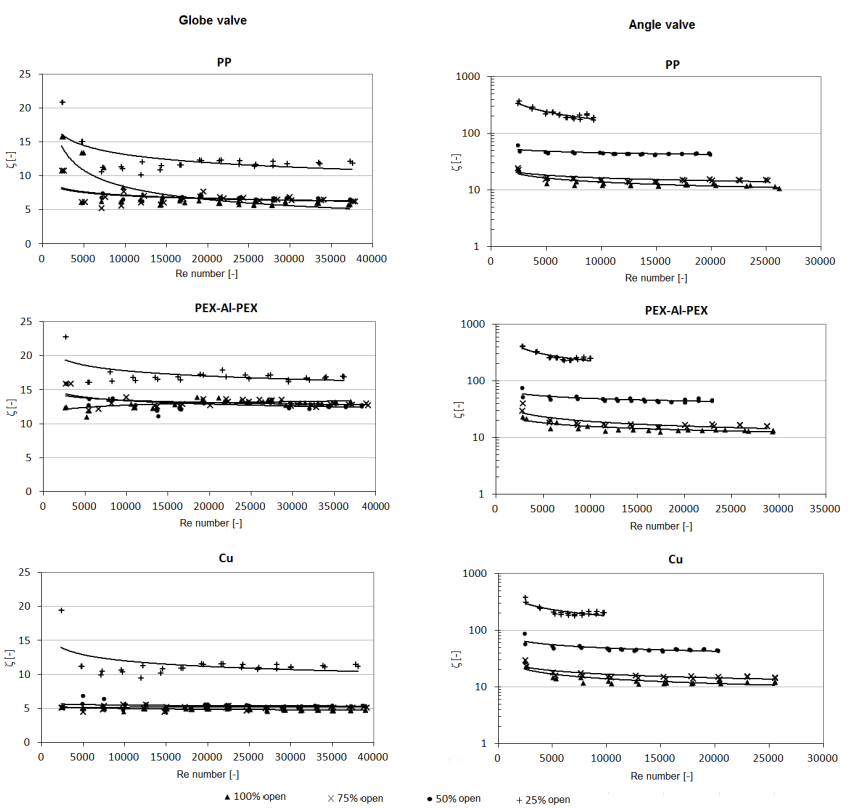

Fig. 3. Coefficients of minor pressure loss in relation to Reynolds number and degree of valve opening.

Results of measurement presented in Fig. 3 showed the dependence between values of minor loss coefficients for tested values together with fittings and Reynolds number. Additionally, there is a noticeable increase in values of coefficients $\varsigma$ in relation to degree of valve closure. For the valve installed on polypropylene pipe with a change in degree of opening from 100 to $25 \%$, the mean value of coefficient $\varsigma$ increased by approx. $70 \%$ : from 7.3 to 20.9 . On the other hand, for the valve installed on PEX-Al-PEX and $\mathrm{Cu}$ pipe there was observed increase of $33 \%(16.2-22.8)$ and $128 \%(6.9-19.5)$, respectively. There was also noted dependence of decreasing values of $\varsigma=f(R e)$ for each of opening degree of tested valves for which decrease in the determined value was inversely to the decreased valve opening. In the case of the $25 \%$ globe valve opening, the value of minor loss coefficient decreased from about 20.9 to 7.3 for the valve installed on PP pipe, from 22.9 to 16.2 for PEX-Al-PEX pipe and from 19.5 to 6.85 for $\mathrm{Cu}$ pipe, for Reynolds number in the range of approx. $2500-38000$. Similarly, a significant increase in values of minor loss coefficients, depending on the degree of valve opening/closure, was observed for the angle valve installed on the tested pipes. However, both the values of minor loss coefficients and the increment of these values, due to angle valve's construction are considerably higher. In the case of the valve installed on polypropylene pipe, an increase in values of $\varsigma$ was observed, caused by valve closing from full opening to $25 \%$, from accordingly 13.6 to 219.3 , which is increase of over $1500 \%$. Similar values were observed for the angle valve installed on the other two pipe materials: an increase from 15 to 163.9 (over 
Table 1. Characteristic values of minor pressure loss coefficients for studied valves.

\begin{tabular}{|c|c|c|c|c|c|c|c|c|c|}
\hline \multirow{3}{*}{ 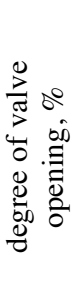 } & \multicolumn{3}{|c|}{ PP } & \multicolumn{3}{|c|}{ PEX/Al/PEX } & \multicolumn{3}{|c|}{$\mathrm{Cu}$} \\
\hline & $\begin{array}{l}. \Xi \\
\stackrel{\Xi}{\omega}\end{array}$ & $\begin{array}{l}{ }^{\infty} \\
\vec{\sigma} \\
\omega\end{array}$ & $\begin{array}{l}\underset{\Xi}{\leftrightarrows} \\
\underset{\omega}{\Xi}\end{array}$ & 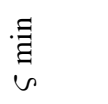 & $\begin{array}{l}\infty 0 \\
\vec{\pi} \\
\omega\end{array}$ & $\begin{array}{l}\underset{\Xi}{\Xi} \\
\stackrel{\Xi}{\omega}\end{array}$ & $\begin{array}{l}\cdot \Xi \Xi \\
\text { 的 }\end{array}$ & $\begin{array}{l}\infty 0 \\
\vec{\pi} \\
i\end{array}$ & $\begin{array}{l}\underset{\Xi}{\Xi} \\
\text { 心 } \\
\omega\end{array}$ \\
\hline & - & - & - & - & - & - & - & - & - \\
\hline \multicolumn{10}{|c|}{ Globe valve } \\
\hline 100 & 3.67 & 6.96 & 15.83 & 11.05 & 13.04 & 14.17 & 4.50 & 4.85 & 5.45 \\
\hline 75 & 0.54 & 6.45 & 10.86 & 11.99 & 13.31 & 19.69 & 3.40 & 5.27 & 10.04 \\
\hline 50 & 0.54 & 6.59 & 10.76 & 11.11 & 13.02 & 15.91 & 4.78 & 5.43 & 6.85 \\
\hline 25 & 7.34 & 11.81 & 20.89 & 16.18 & 17.30 & 22.83 & 6.85 & 11.08 & 19.48 \\
\hline \multicolumn{10}{|c|}{ Angle valve } \\
\hline 100 & 10.71 & 13.63 & 23.25 & 12.63 & 14.96 & 23.32 & 11.47 & 13.83 & 28.27 \\
\hline 75 & 14.08 & 16.17 & 24.82 & 15.00 & 18.53 & 40.02 & 13.80 & 16.56 & 29.94 \\
\hline 50 & 41.61 & 45.11 & 61.56 & 42.20 & 47.86 & 75.09 & 42.29 & 48.40 & 86.62 \\
\hline 25 & 171.51 & 219.32 & 368.97 & 229.20 & 263.89 & 409.12 & 181.18 & 208.44 & 313.87 \\
\hline
\end{tabular}

$1660 \%$ ) and from 13.8 to 208.4 (over $1400 \%$ ), accordingly for multilayer PEX-Al-PEX pipe and $\mathrm{Cu}$ pipe.

There was also a decrease in $\varsigma$ values with increasing flow rate and Reynolds number in consequence, for a given degree of valve opening/closure. For example, for the largest closure (25\% valve opening), the value of coefficient $\varsigma$ varied in the following ranges: $369-171.5$, 409.11- 229.2 and 313.9 - 181.2, respectively for the valve installed on PP, PEX-Al-PEX and Cu pipes.

For both valves, the highest values of minor loss coefficients for a given degree of valve closure were observed for valves installed on PEX-Al-PEX pipe using separable couplers.

The performed statistical analyses showed significance of the observed differences between the average values of minor pressure losses and minor loss coefficients for a given degree of opening of valve installed on PEX-Al-PEX pipe and the values noted for the other two tested pipe materials. Additionally, multiple comparisons and post-hoc tests showed no statistically significant differences between the mean values of flow resistances for fittings installed on PP and $\mathrm{Cu}$ pipes. This effect is likely to be explained by approximate shape of flow geometry resultant from realization of socket solder and welded joints. However, in our opinion, this issue requires further researches (e.g. CFD model studies) for the purpose of assessing the influence of flow geometry on velocity spatial distribution and turbulence intensity by the water flow through the tested valve installed on described pipes using separable couplers.

\section{Summary}

Conducted researches of hydraulic resistances generated by two tested valves installed on three different pipe's materials, showed the dependence between the values of the observed pressure losses and minor loss coefficients and the degree of valve closure. Additionally, the influence of the way of installing valve on a given pipe material on tested flow resistances was observed. Both tested valves were significantly different in their construction, so it is understandable that there are significant differences between the defined minor pressure losses and minor loss coefficients for the same degree of valve opening/closure. Defined minor loss coefficients for the angle valve are few to a dozen times higher than coefficients for the globe valve.

Additionally, an increase of minor loss coefficient for angle valve was observed up to dozen times in the event of changing valve opening from fully open to $25 \%$ of opening.

The above results suggest that the sudden increase of generated hydraulic resistances, significantly lowering 
the pressure behind the discussed valve, makes this valve not to be used as a control valve, as it may adversely affect the operation of domestic appliances connected to the water supply by the tested valve.

The researches also showed that the installation of the tested valves using separable couplers directly affects the value of minor loss coefficients. For each tested degree of valve opening, the highest values of observed pressure losses and determined coefficients $\varsigma$ were noted for valves installed on multilayer PEX-Al-PEX pipe.

The determined mean values of minor loss coefficients for fully open globe valve installed on polypropylene and copper pipe were similar to the literature values suggested in the design guidelines. In the event of valve installation on the multilayer pipe, the values of coefficient $\varsigma$ for the full opening of the globe valve were higher than the suggested values for design and belonged to the range known from scientific publications. The average values of minor loss coefficient for full opening of the tested angle valve in each way of its installing on tested materials far exceeded the literature values.

In our opinion, the design calculations of domestic installations should take into account not only the resistances generated by coupler but also the influence of the resistances located close to each other (set of the valve and couplers).

\section{References}

1. Installation system Solter PEX, Technical guide, www.hydrosolar.pl

2. I. Cisowska, A. Kotowski, FCEE 8, (2006)

3. P. Grajper, J. Smołka, Gaz Woda, 7/8 (2010)

4. K. Weinerowska-Bords, Instal 6, (2014)

5. Polish Design Standard PN-M-34034:1976

6. T. Siwiec, D. Morawski, G. Karaban, Gaz Woda 2, (2002)

7. I. Cisowska, A. Kotowski, Gaz Woda 10, (2004)

8. K. Strzelecka, K. Jeżowiecka-Kabsch, Ochr. Srod. 30, 2 (2008)

9. K. Strzelecka, K. Jeżowiecka-Kabsch, Ochr. Środ. 32, 1 (2010)

10. M.K. Widomski, A. Musz, M. Iwanek, Gaz Woda 9, (2012)

11. F.G. Piechurski, Water and sewage installations, 3rd Scientific and Technical Conference (WarsawDębe, 2009)

12. K. Dul, M.K. Widomski, A. Musz-Pomorska, Instal, 11, 36-39 (2015)

13. N. Gietka, Acta Sci. Pol. Formatio Circumiectus 14, 1 (2015)

14. M. Kalenik, Rynek instalacyjny 11, (2013)

15. D.G. Newnan, Fundamentals of Engineering (Chicago: Kaplan AEC Education, 2004)
16. B.E. Larock, R.W. Jeppson, G.Z. Watters, Hydraulics of Pipeline Systems (Florida: CRC Press, 2000)

17. W. Kołodziejczyk, M. Płuciennik, Guidelines for the design of central heating installations (Warsaw: COBRTI INSTAL, 2001)

18. E. Nowakowski, Gaz Woda 4, 20-23 (2005)

19. A. Górecki, Z. Fedorczyk, J. Płachta, M. Płuciennik, A. Rutkiewicz, W. Stefański, J. Zimmer, Water, heating and gas installations, for gaseous fuel, made of copper pipes. Application and design guidelines (Wrocław: Biblioteka Polskiego Centrum promocji Miedzi, 2009)

20. Kan Therm system. Designer's guide and contractors, pl.kan-therm.com

21. Frankische. System alpex Export 16-75mm. Technical catalog. www.viessmann.com

22. TECE. Universal installation system. Technical information, www.tece.pl

23. Systempol. Water installations. Technical reference for indoor installation of cold and hot water, heating systems. www.detalmet.pl

24. Polish Design Standard PN-EN 1267:2012. 